\title{
PRIMA: Formando agentes multiplicadores em Gerência Pública
}

\author{
Maria Carolina Vasconcelos Freire \\ Diretora-adjunta do CEDAM
}

Em convênio com a École Nationale d' Administration Publique ENAP Quebec/Canadá, o Centro de Desenvolvimento da Administração Pública - CEDAM - realizou, no último mês de maio, o curso Programa Integrado de Gestão - PRIMA.

O curso teve como objetivo oferecer uma oportunidade de apoio e de desenvolvimento ao processo de aperfeiçoamento de dirigentes públicos, em conformidade com as diretrizes traçadas pelo Decreto presidencial que instituiu o Sistema de Carreira (Decreto-lei n. 2.403, de 21 de dezembro de 1987). Isso porque, ao formar a primeira turma, a FUNCEP e o CEDAM dão um impulso em direção à valorização do servidor e do aperfeiçoamento da gerência pública no País, mediante a ação multiplicadora que se propagará não somente no nível do governo federal mas, também, no nível dos governos estaduais e municipais.

A ENAP canadense enviou para esse curso dois de seus mais capacitados professores, de competência e experiência internacionalmente reconhecidas, para ministrar o PRIMA no CEDAM, programa realizado pela primeira vez na América Latina. Os professores foram PAUL ÉMOND, PhD em Administração Pública, criador da metodologia, implantada no Canadá e divulgada com êxito para outros países, inclusive via satélite para paises de língua francesa, e JACQUES PELLETIER, também PhD em Administração Pública e Diretor Regional da Comissão da Função Pública do Canadá. Ambos vêm-se dedicando à formação e aperfeiçoamento de dirigentes públicos no Canadá e em outros paises.

Em atendimento às diretrizes traçadas pela Reforma Administrativa, no que se refere à descentralização de ações, o CEDAM contemplou nesse evento uma clientela formada não apenas por servidores públicos da administração federal, direta e indireta, mas também por aqueles atuantes na máquina administrativa dos Estados. Com isso, contribuiu o CEDAM para a formação de agentes multiplicadores que irão agilizar a Reforma que se processa nos Estados e aprimorar o desempenho da máquina administrativa estadual.

\section{PRIMA, contribuição do \\ CEDAM, para agilizar a Reforma}

As Regiões Nordeste, Sul, Sudeste e Centro-Oeste eștiveram representadas, por intermédio da participação de alunos dos estados da Bahia, Pernambuco, Santa Catarina, São Paulo e Distrito Federal.

\section{O QUE É O PRIMA}

O Programa Integrado de Gestão é um instrumento que permite aos gerentes fazer relações constantes entre as responsabilidades de sua organização e o ambiente externo e interno em que ela está inserida.

Se considerarmos a situação mundial, apenas no que diz respeito à competição internacional, e a gestão interna de diferentes organizações públicas do país, verificamos que elas se revelam cada vez mais complexas e exigem mudanças estruturais na administração pública.

Grande parte de gerentes públicos enfrenta o problema de produzir mais, com cada vez menos recursos. Esse desafio pode levar os gerentes a sentirem-se despreparados para encontrar respostas que satisfaçam às exigências inerentes às suas funções.

Diante de tais desafios, os gerentes mais capacitados serão aqueles que apresentarem modificaçōes em seus comportamentos e atitudes $d e$ modo a adquirir novos conhecimen tos e práticas de novos hábitos. Serão esses os gerentes que tornarão suas organizaçōes eficazes, eficientes e produtivas.

O PRIMA é um programa flexivel e seu enfoque possibilita aos participantes a adaptação da metodologia a diferentes organizações.

Centralizando-se nos serviços e resultados da organização, a filosofia do PRIMA prende-se às necessidades dos beneficentes e aos serviços ou produtos que a organização deve produzir ou oferecer.

O PRIMA não promove apenas a eficácia e eficiência, mas também propõe técnicas, o deservolvimento de habilidades, e preocupa-se com a produtividade e qualidade de vida no trabalho.

Ao final do programa os alunos desenvolveram um material instrucional adaptado à realidade brasileira

O CEDAM sabe que, para fazer frente à Reforma Administrativa e ao Sistema de Carreira e atender às diretrizes de valorização do servidor, faz-se necessária a promoção e estimulação de agentes de mudança.

Os agentes são de grande importância, pois são eles os catalisadores das forças positivas que operam a organização e a fazem alcançar os re- 


\section{IDÉIAS}

sultados pretendidos.

Ao oferecer o PRIMA, o CEDAM tem a certeza de ter capacitado a 1 . turma de gerentes públicos capaz de promover e estimular, no âmbito de suas próprias organizações, as mudanças necessárias para que elas possam cumprir sua função social.

Ao longo de quase um mês do dia 09 de maio ao 03 de junho, os professores e vinte alunos trabalharam in- tensivamente, desenvolveram novas técnicas de gerenciamento e habilidades pessoais e produziram, ao final do Programa, um material instrucional adaptado à realidade brasileira.

O produto final do trabalho, apresentado sob a forma de um plano de ação, em muito contribuirá para o crescimento da eficácia e eficiência pessoais dos gerentes públicos, bem como das organizações pelas quais os participantes são responsáveis.

O alto nível do Curso oferecido pelo CEDAM, evidenciado pelo preparo técnico e científico do corpo docente da ENAP-Quebec e pela qualificação da clientela participante, nos dá a certeza de que a FUNCEP e o CEDAM prestam contribuição efetiva ao aperfeiçoamento do servidor público e de que o efeito multiplicador do programa que acabamos de realizar, agilizará o aprimoramento da máquina administrativa governamental.

O projeto piloto do programa PRIMA, com a formação da primeira turma, transforma-se doravante, em um programa permanente oferecido pelo CEDAM, vez que os direitos de reprodução da metodologia no Brasil foram repassados pela ENAP - Quebec à FUNCEP-CEDAM.

\section{FUNCEP/PUBLICAC̣ÕES}

Um acervo de publicações sobre administração pública. Edições que não são encontradas com facilidade na linha editorial de nossos livreiros.

\section{COLEC̣ÃO ESTUDOS POLÍTICOS - EP}

Estender, para além das normas e rotinas administrativas, as preocupações relativas aos problemas da Administração. Ao mesmo tempo apresentar textos produzidos por estudiosos que, no desempenho de suas funções, assumiram papéis importantes nos destinos da nação.

Mínimo de 60 páginas; formato $14,5 \times 20,5$ cm; capa: papel chambril $120 \mathrm{gr}, 2$ cores; plastificada; miolo: papel off-set, $75 \mathrm{gr}$.

\section{TITULO \\ CÓDIGO}

Presidencialismo e Parlamentarismo - José Augusto $301 \quad C z \$ 600,00$ O Regime Parlamentarista e a Realidade Brasileira - Tancredo Neves

Parlamentarismo ao Alcance de Todos - Raul Pilla
Parlamentarismo e Presidencialismo na Realidade Brasileira - Sylvio Romero

304 $C z \$ 420$

Cartilha do Parlamentarismo - João Camilo de Oliveira Torres

Pródomos do Governo de Gabinete - Aliomar Baleeiro

O Novo Parlamentarismo - Vamireh Chacon

\section{$305 \mathrm{Cz} \$ 360,00$}

306

$\mathrm{Cz} \$ 330,00$

307

Cz\$ 370

TOTAL Cz\$2.690,00
PREÇO

Coleção EP - 7 volumes: Código 300 preço especial Cz\$1.900,00

Cortesia - Anais dos Seminários: Presidencialismo/ Parlamentarismo Nordeste e a Constituinte

Pedidos - Podem ser feitos pelo correio,

$C z \$ 340,00$ somente através de cheques, à FUNCEP/PUBLICAÇÕES Caixa Postal 12-2555 70.610 - Brasília/DF 